\title{
Practice of dieting and its complications among the females.
}

\author{
Alamgir Khan ${ }^{1 *}$, Salahuddin Khan', Syed Zia-ul-Islam, Dilabaz Khan², Dilabaz Khan ${ }^{3}$, Manzoor Khan ${ }^{4}$ \\ ${ }^{1}$ Department of Sports Science and Physical Education, Gomal University, KP, Pakistan \\ ${ }^{2}$ Government Degree College, KP, Pakistan \\ ${ }^{3}$ Department of Higher Education, KP, Pakistan \\ ${ }^{4}$ Department of Education, Hazara University Manshera, KP, Pakistan
}

\begin{abstract}
This research study was primarily aimed to examine the perception of female society about the practice of dieting and its complications. Twenty (20) females were randomly taken as sample of the study from the different departments of Gomal University KP Pakistan. For the collection of data, the researcher developed a closed form of questionnaire. The developed questionnaire was personally distributed by the researcher among the respondents and collected back after getting it filled by the respondents. The collected data were tabulated and analyzed by using percentage as a statistical tool. After analysis, the researcher arrived at conclusion that due to unfamiliarity with dieting practice, many females may lead to different health complications.
\end{abstract}

Keywords: Female, Dieting, Complication, Gomal University, Dera Ismail Khan.

Accepted on October 05, 2017

\section{Introduction}

\section{Background of the study}

In present era, we are in global race of changing the life style. Society adopted different systems for changing the life style by having no awareness that either these entire systems are useful or not? In present day life, both human segments are adopting a variety of systems for a good physical appearance. All these systems have their own procedures for their adaptation. Dieting is a new fashion and a very huge number of females adopting this newly developed fashion. Due to unawareness or unfamiliarity with the adaptation of this new fashion or style, many of the females lead to life intimidating problems. What are the complications of dieting practice? To discover the facts the researcher intends to conduct a research study titled "Practice of Dieting and its Complications among the Females".

\section{Objectives of the study}

To assess the perceptions of female society about the practice of dieting and its complications.

\section{Significance of the study}

This research study is helpful in creating awareness among the female society about the complications of dieting as well as the proper adaptation of dieting practice according to the need and requirements of the body.

\section{Review of Related Literature}

\section{Balanced diet and its role in healthy life style}

According to Solomons and Gross [1] due to changes in lifestyle one have a very little time to really think that the food we are eating is a healthy or not. Globalization has seriously affected one's eating habits and enforced many people to consume fancy and high calories fast foods, popularly known as Junk foods.
Mann et al. [2] stated that health experts always recommend diets for the well maintenance of health. Lack of sufficient intake of diet adversely affects the functional capacity of the body. Balanced or healthy diet refers to the diet which maintain and promote health by WHO in 2003 . It is estimated that $80 \%$ of all cardiovascular diseases, $90 \%$ of all type 2 diabetes and $30 \%$ of all cancer could be prevented by eating a healthy diet, increasing physical activity and avoiding smoking WHO in 2003.

According to, diet is basic element of life which makes one [3]

1. To perform the activities of daily life

2. To avoid the health problems

3. To stay healthy

Dieting, complications of dieting and symptoms of complications related to dieting?

It is the practice of using food in a controlled and supervised fashion to decrease, maintain, or increase body weight. It is commonly used by all those people who have the problem of obesity or overweight (Wikipedia). Short-term dieting may cause poor or improper body growth and development. Dieting may cause weight loss which is beneficial to those classified as unhealthy, may slightly increase the mortality rate for individuals who are otherwise healthy [4].

Junk food (empty calorie food) is a high calorie or calorie rich food which lacks in micronutrients such as vitamins, minerals, or amino acids, and fibers but has high energy (calories). These foods don't contain the nutrients that your body needs to stay healthy [4].

\section{Complications of dieting}

Demands of the present day force one to change the natural style of the body. There is a long list of the effects of trying to change your natural body size and shape: 
- Un-satisfaction in daily life activities.

- Preoccupation with food, weight and shape.

- Potential loss of friendships and an active social life, and

- Loss of enjoyment during participation in sport activities.

According to Bell Vita (nd) long term dieting habits adversely affects the body such as

1. A loss of significant body mass including muscle mass.

2. Organ failure at minor, moderate, or severe levels due to poor nutritional intake.

3. Malnutrition.

4. Neurological implications.

5. Heart-related complications.

6. Immune-related complications.

7. The body enters starvation mode.

8. Lack of energy and focus.

9. Lack of mental clarity.

10. High blood pressure.

Attention may be given to the complications caused by dieting. It directly impact upon the physical as well as mental health of a person. Looking for medical care for the health complaints and counseling or therapy sessions for the emotional component of this condition may be necessary in some situations. Family and friends can often help by being helpful and helping to educate the individual to adopt proper dieting procedures [5].

\section{Weight reduction}

Human body assumes the daily vicissitudes very effortlessly. However, when it takes place then it's become so hard to get your body back to the earlier position. Consumption of high caloric foods may cause obesity. Likewise, treatment and recovery of obesity need more time and experts consultations. According to [6] if you want to reduce your body weight then you can get help from the following few tips [7] (Figures 1 and 2).

- Eat a high-protein breakfast.

- Avoid sugary drinks and fruit juice.

- Drink water a half hour before meals.

- Choose weight loss-friendly foods.

- Drink coffee or tea.

- Eat mostly whole, unprocessed foods.

- Eat your food slowly.

- Use smaller plates.

- Get a good night's sleep, every night

According to Australian Bureau of Statistics [8,9] diet and exercise both are necessary for controlling the weight of the body and for reducing body weight one needs to

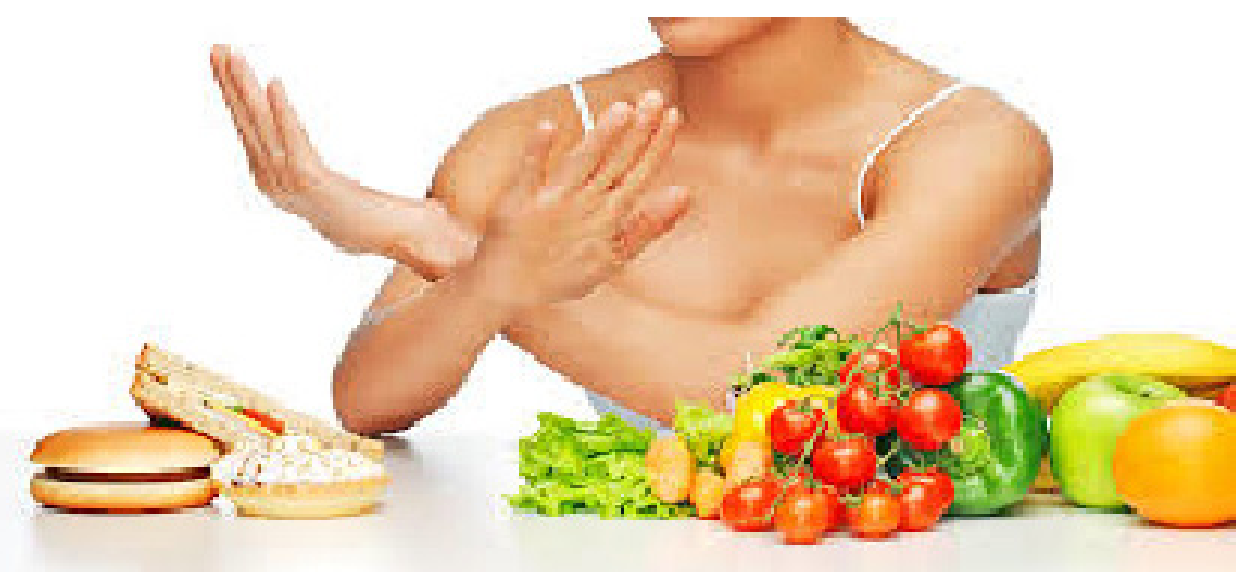

Figure 1. Say no to junk food and have healthy food.
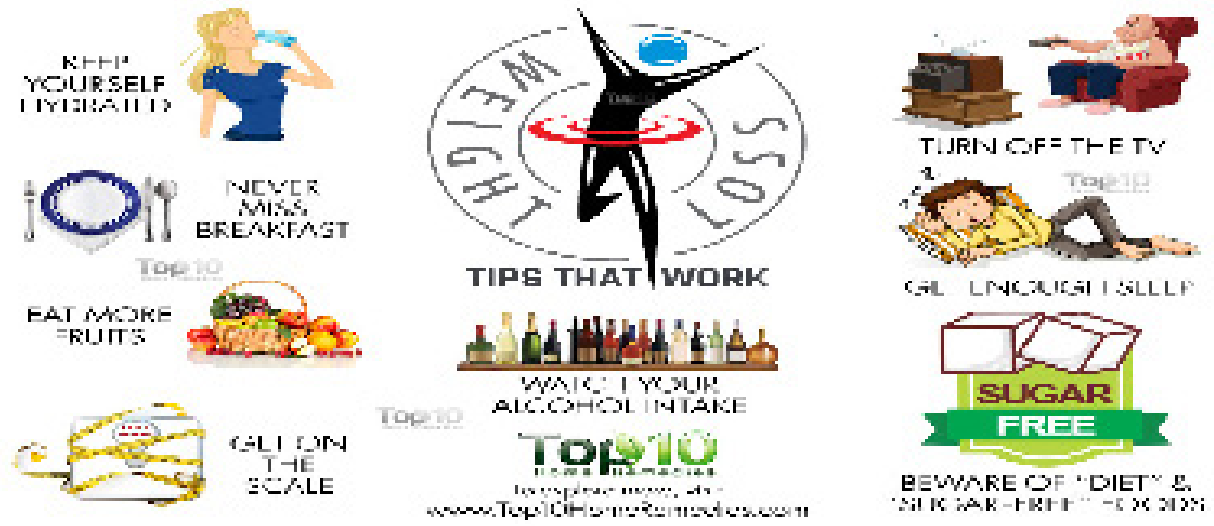

Figure 2. Tips for weight loss. 
- Eat according to needs of the body.

- Eat according to the nature of activity.

- Perform regular exercise.

\section{Causes of overweight}

According Frenn et al. [10] to many factors may influence one's weight, overweight and obesity occur mainly because of taking too much energy and consuming too little. Likewise, genetic and environmental factors also play a role in the above stated aspects of the body (Figure 3) [11].

According to Functional Medical System [12] the main causes of overweight among the children are

- Eating more without exercise.

- Social cultural conditions.

- Unfamiliarity about the daily intake of food.

According to Neumark-Sztainer [13], along with so many other factors, following are the some other factors caused obesity among the children

- Excessive and wrong nutritional habits.

- Insufficient physical activity.

- Age.

- Gender.

- Education level.

- Socio-cultural circumstances.

- Income level.

- Hormonal and metabolic factors.

- Genetic factors.

- Psychological problems.

- Application of too low caloric diets with frequent intervals.
- Smoking-alcohol consumption.

- Some medications (anti-depressants etc.).

- Number of births and time between births.

\section{Discussion}

\section{Findings of the study}

The following findings, based on analysis, are drawn by the researcher (Table 1)

1. Majority of the respondents opined that they are adopting dieting practice but having no familiarity with dieting practice.

2. Majority of the respondents opined that they have no awareness about daily recommended intake of food.

3. Majority of the respondents opined that they are adopting dieting practice without exercise.

4. Majority of the respondents opined that they have a lot of physical and mental problems due to the adaptation of dieting practice.

5. Majority of the respondents opined that they are unsatisfied with their daily activities due to the adaptation of dieting practice.

\section{Conclusion of the Study}

On the basis analysis, the researcher arrived at the conclusion that due to unfamiliarity with practice of dieting, many females lead to different health complications.

\section{Recommendations of the Study}

On the basis of the findings, the researcher recommended that

1. Female society may be made aware about dieting practice by conducting different awareness programs.

2. Views of the health experts may be taken while adopting the practice of dieting.

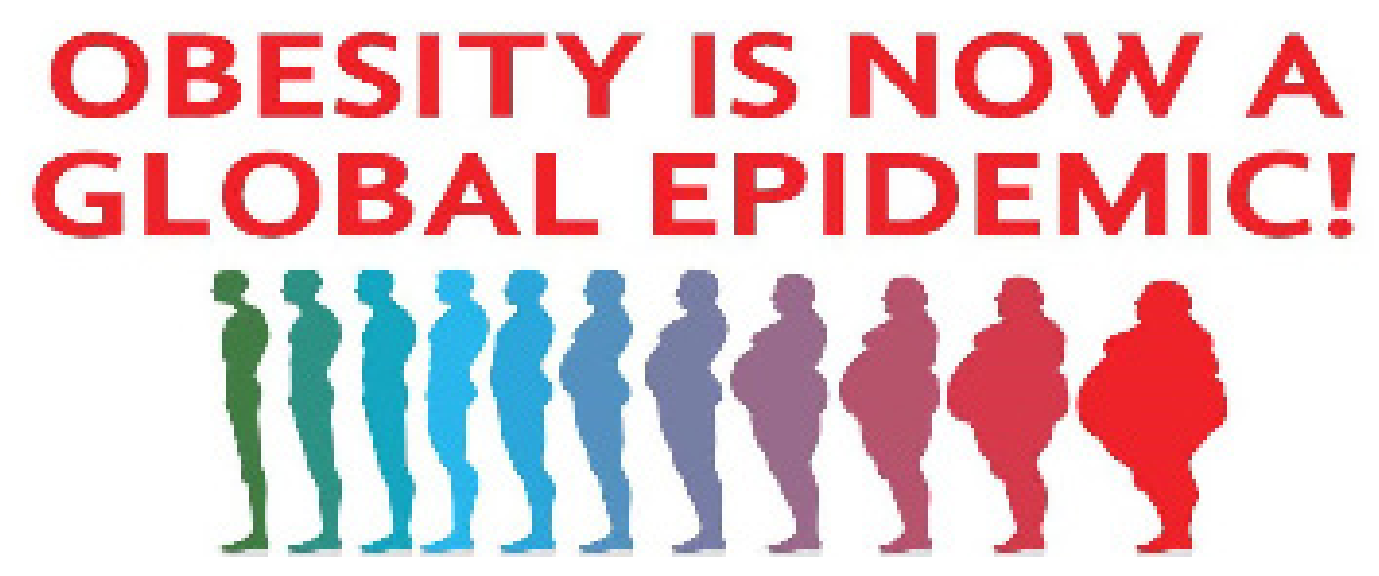

Figure 3. Obesity is the cause due to over weight. 
Table 1. Data analysis.

\begin{tabular}{|c|c|c|c|c|c|c|}
\hline S.No & Statement & Yes & $\%$ & No & $\%$ & Total \\
\hline 1. & Are you adopting dieting practice & 20 & $100 \%$ & 03 & $05 \%$ & 20 \\
\hline 2. & Do you familiar with the proper procedures of dieting practice & 12 & $60 \%$ & 08 & $40 \%$ & 20 \\
\hline 3. & $\begin{array}{l}\text { Do you have any nutritional chart for using diet according to the daily need } \\
\text { of your body }\end{array}$ & 12 & $60 \%$ & 08 & 40 & 20 \\
\hline 4. & Do you perform exercise with dieting practice & 10 & $50 \%$ & 10 & $50 \%$ & 20 \\
\hline 5. & Do you want to make yourself smart by using dieting practice & 20 & $100 \%$ & 00 & $00 \%$ & 20 \\
\hline 6. & Do you feeling any physical weakness after adopting dieting practice & 20 & $100 \%$ & 00 & $00 \%$ & 20 \\
\hline 7. & Do you feeling any mental weakness after adopting dieting practice & 20 & $100 \%$ & 00 & $00 \%$ & 20 \\
\hline 8. & Do you satisfied with your daily activities after adopting dieting practice & 15 & $75 \%$ & 05 & $25 \%$ & 20 \\
\hline 9. & $\begin{array}{l}\text { Do you feel enjoy and satisfaction with your friends and classmates after } \\
\text { adopting dieting practice }\end{array}$ & 14 & $70 \%$ & 06 & $30 \%$ & 20 \\
\hline 10. & $\begin{array}{c}\text { Do you want to participate in any playful activity after adopting dieting } \\
\text { practice }\end{array}$ & 18 & $90 \%$ & 02 & $10 \%$ & 20 \\
\hline
\end{tabular}

\section{References}

1. Solomons NW, Gross R. Urban nutrition in developing countries. Nutr Rev. 2005;53: 90-5.

2. Mann T, Tomiyama AJ, Westling E, et al. Medicare's search for effective obesity treatments: Diets are not the answer. Am Psychol. 2007;62:220-33.

3. Leino-Kilpi H, Johansson KMRN, Kaljonen, A, et al. Patient education and health-related quality of Life: Surgical hospital patients as a case in point. J Nurs Care Qual. 2005;20:307-316.

4. McNamara JR, Green JP. Decreasing junk-food consumption through the use of self-management procedures. Psychol Rep. 1991;69:19-22.

5. Cordain, L. AARP The paleo diet revised: Lose weight and get healthy by eating the foods you were designed to eat. John Wiley \& Sons., USA. 2012.

6. http://www.healthline.com/nutrition/how-to-lose-weightas-fast-as-possible\#section 1
7. www.top10homeremedies.com/news-facts/10-weight-losstips-that-work.html

8. Australian Bureau of Statistics. Australian Health Survey: Nutrition first results-foods and nutrients, 2011-12. ABS cat. no. 4364.0.55.007. Canberra: ABS. 2014.

9. www.http://healthyeaton.com/break-free-from-the-dietingcycle/

10. Frenn M, Malin S, Villarruel AM, et al. Determinants of physical activity and low-fat diet among low income African American and Hispanic middle school students. Public Health Nurs. 2005;22:89-97.

11. www.http://functionalmedsystem.com/en/obesity-andoverweight/

12. Ministry of Health of Turkey (nd). Causes of overweight and obesity. Directorate of primary effective obesity treatments: Diets are not the answer. Am Psychol. 62;2005:220-233.

13. Neumark-Sztainer D. I'm, like, SO fat!: Helping your teen make healthy choices about eating and exercise in a weightobsessed world. Guilford Press. 2005.

\section{*Correspondence to:}

Alamgir Khan

Department of Sports Science and Physical Education Gomal University

Khyber Pakhtoonkhwa

Pakistan

Tel: +92 3105243607

E-mail: alamgir1989@hotmail.com 